\title{
Implementation of an Optimal Control System of Distributed Power Using Microgrid Based Load Prediction Method
}

\author{
Jin-Gyu Chang ${ }^{1}$ and Moon-Sik Kang ${ }^{2}$ \\ Dept. of Electronic Engineering, Gangneung Wonju National University \\ Gangneung\&Wonju, South Korea \\ ${ }^{1} J k c h a n g 0928 @ g w n u . a c . k r,{ }^{2}$ mskang@gwnu.ac.kr
}

\begin{abstract}
In this paper, we propose an optimal control scheme of distributed power using load prediction model for the efficient operation and management based on microgrid technology. The microgrid network as one type of energy networks can be used to supply the electrical or heat energy efficiently, which can be applied to an external power network controlled by an energy management system (EMS) or to the form of a small renewable energy network that operates independently. The proposed system is designed to operate according to the charging and discharging plan for energy storage devices, and it is implemented to maximize optimal control of distributed power source for the efficient operation and management based on microgrid technology. Finally, performance evaluation of the proposed system was performed considering weather data and power load prediction.
\end{abstract}

Keywords: microgrid network, distributed power system, optimal control, load prediction, operation and management

\section{Introduction}

In recent years, there has been a growing interest in providing a stable supply of electric power. Therefore, a demand prediction model of electric energy is required, which should take into account changes in demand for electric power and variability in temperature. In addition, it is necessary to establish infrastructure of distributed power source, to require technological development and deregulation, to activate new energy business model, to expand the supply of new and renewable energy, and to activate distributed power. The microgrid network would be a type of energy networks for supplying the electrical or heat energy in the independent or connected manner. It is usually operated in conjunction with the distribution networks, which are divided into the grid-connected type or the single type grid. In the event of a fault in the power system or of being degraded in the power quality, the grid-connected type switches to the single type micro-grid. On the other hand, the single type micro-grid is designed to supply the power to remote sites being not supplied with commercial power. The effective operation management of distributed power facilities is required for spreading distributed power supply, expanding both the private power generation facilities and the supply of new and renewable energy, and for strengthening the competitiveness of the local electricity business.

Microgrid technology has been developed and commercialized mainly in the United States and Europe. The Grid IQ Microgrid Control System developed by GE in the United States includes integrated control of distributed resources, output control, independent operation mode support, and grid support functions. There are differences in the research and development and demonstration projects related to micro grid in each country. Europe

Received (June 26, 2017), Review Result (August 9, 2017), Accepted (August 21, 2017) 
aims to increase energy efficiency by designing and optimizing microgrid network through demonstration projects. By integrating distributed resources, it is possible to realize the distribution system of new and renewable energy efficiently and to reduce the greenhouse gas exhaustion. The companies have strategies to ensure the efficiency, reliability, and economy of the microgrid. The United States is carrying out various pilot projects to integrate and operate dispersed energy resources including new and renewable energy linked to distribution, centering on private companies. With GE as the center, industry, consulting and engineering companies, Research institutes, and government agencies (Department of Energy, Department of Defense) are actively supporting business by forming value chain. Under the support of government organizations (NEDO, NEF, Central Research Institute of Electric Power), Japan continues to pursue empirical research focusing on companies such as Mitsubishi Electric. In particular, Japan is investing heavily in international joint research and international empirical sites.

Therefore, we have studied the prediction model for microgrid load prediction considering both the distributed power generation and the charge/discharge planning for energy storage devices, Also our study on the distributed power management scheme will continue. In this paper, we describe the results of a distributed power optimal control technique to optimally control and operate a distributed power supply using an active device for the microgrid based distributed power control linked to new and renewable energy storage devices. The optimal control system proposed in this paper is designed to maximize economic efficiency and operational efficiency by unifying operation planning, control and monitoring and operating under optimal conditions for efficient operation management of distributed power facilities based on microgrid. The proposed system is implemented to enable the operation planning, control and monitoring through efficient operation management of the distributed power supply facilities in the microgrid, and its performance is analyzed and evaluated.

The rest of this paper is organized as follows. The next section describes the related research with a focus on microgrid technology and control techniques. The proposed distributed power optimal control system will be described in section III. Section IV describes performance evaluations and discussion of the effect of the proposed scheme. Finally, we conclude this paper in the last section.

\section{Related Research Works}

Domestic electric power IT projects, K-MEG projects, and Jeju demonstration complexes have been partially constructed. However, there is still a lack of real-scale microgrid construction for actual customers. The fundamental research on EMS, design, and analysis techniques is underway today, but the progress of professional engineering companies or commercialization process is delayed. Currently, domestic technology level is in development stage of government-led demonstration technology. A 200KW microgrid demonstration site was installed in the Electric Power Research Institute and also a $120-\mathrm{KW}$ microgrid was built by the Korea Institute of Electrical and Electronic Engineers (KRII). Since 2014, the micro grid platform business has been in full swing in Korea. Based on the experience of element device development and operation, it is expected that the stand-alone micro grid will be supplied domestically and advanced into overseas markets. In addition, it is expected that the technology development, demonstration, and commercialization for campus and military microgrid will continue.

A distributed power source means a power source capable of being distributed in a small scale near a power consumption area, which is distinguished from a large-scale concentrated power source. Also it includes power generation facilities using renewable energy and renewable energy and generating facilities corresponding to private electric utilities. In many cases, collective energy (Cogeneration power generation) is not directly linked to the distributed power source, but is highly favorable for their inclusion due to 
the high efficiency of the cogeneration and environmental aspects. Distributed power sources can be classified into collective energy, private generator, and renewable energy. Collective energy means that heat and electricity are produced at the same time and sold exclusively to consumers in the region. On the other hand, private power generation means to produce and consume part of the electricity that is normally needed.

The features of the distributed power supply in relation to the proposed distributed power control and operation system are described as follows. First, it is a relatively smallscale power supply facility that is located dispersedly around or near the power consumption site, and can be installed in the closest proximity to the place of demand, since there are few limitations on location or environment. Second, it is often necessary to intermittently generate electricity in close proximity to the night, daytime or natural environment depending on the generation method, so this must be linked to the existing power system in order to supply stable demand. Third, the power generated by most of the distributed power plants requires economical operation connected with the power storage system rather than directly connected to the system. This is because it produces electricity at a relatively high cost due to low energy density, intermittent operation mode, and the latest equipment, such as high construction costs.

When the distributed power supply is operated in conjunction with the grid, the local voltage fluctuation in the grid may be increased due to the output variation of the grid depending on the characteristics of the distributed power supply. In particular, since the variation of the power generation amount cannot be predicted in advance, the voltage adjustment becomes more difficult in the distributed power source. It is possible to cope with such a problem partially by limiting the introduction capacity of the distributed power source connected to the distribution line, but it is necessary to develop a technology capable of mitigating such a restriction factor. These problems must be solved by complementing the mutual operation of the protection system of the power distribution system and the protection device of the distributed power source. In the case of photovoltaic power generation, it is also necessary to examine whether the new characteristics will be fully analyzed to apply the new protection method. This is because the power supply characteristic is connected to the system through the inverter to the DC power supply differently from the conventional power generation system.

\section{The Proposed Optimal Control System with Prediction Algorithm}

\subsection{Power Load and Prediction Model}

In this study, a fuzzy C-means (FCM)-based polynomial neural network is applied for the prediction model, and its structure is shown in Figure 1. This algorithm consists of three modules, such as a conditional part, a conclusion part, and a reasoning part, where the rule is as shown in equation (1).

$R_{c}$ : If $x_{1}$ is $A_{c 1}$ and $x_{2}$ is $A_{c 2} \ldots$, and $x_{n}$ is $A_{c n}$, then $\mathrm{y}=f_{c}$

Here $R_{c}$ is the $c(c=1, \ldots, k)$-th rule, $A_{c n}$ is the hidden layer, $n$ is the number of input variables, and $\mathrm{f}_{\mathrm{c}}$ is the polynomial function. 


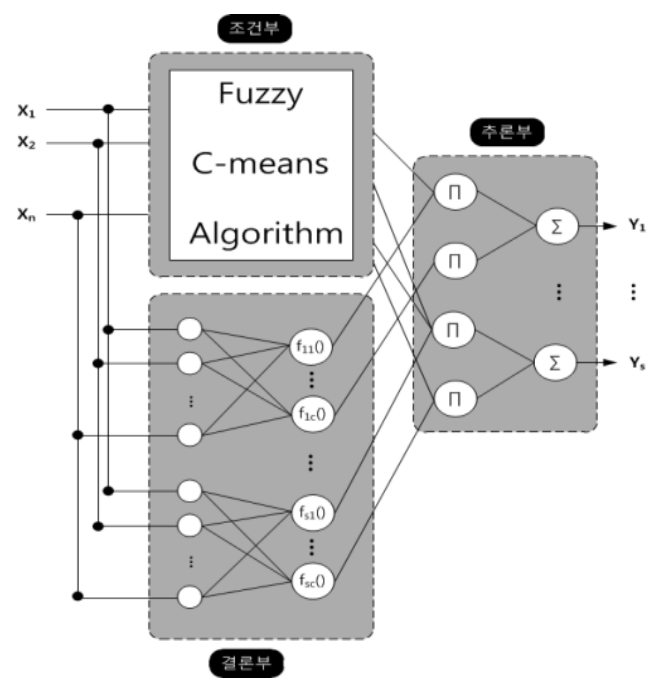

Figure 1. Structure of FCM-based Prediction Model

In the conditional part of the FCM-based polynomial neural network, the operation is performed through FCM clustering of the entire conditional part. The conditional function using FCM clustering divides the input space into $\mathrm{c}$ local regions (number of clusters) to reflect the characteristics of the input data, and outputs the membership degree of each local region as a fuzzy set. FCM clustering minimizes the equation (2), which is an objective function, to obtain the membership value for each cluster of input data.

$\mathrm{Q}=\sum_{i=1}^{c} \sum_{k=1}^{N} u_{i k}^{m}\left\|x_{k}-v_{i}\right\|^{2}$

Here $\mathrm{c}$ means the number of clusters (number of fuzzy rules), $\mathrm{N}$ means the number of input patterns, and $\mathrm{m}$ represents the fuzzy coefficient being greater than 1.0.The term of $x_{k}$ is the k-th input vector and $v_{i}$ is the center of the $\mathrm{i}$-th cluster. Also $u_{i k}$ is a real number between 0 and 1 representing the degree of belonging to the i-th cluster of the k-th data and it satisfies the conditions of equation (3) and equation (4). The \| $\|$ part in the equation (2) means the weighted Euclidean distance expressed by equation (6).

$$
\begin{gathered}
\sum_{i=1}^{c} u_{i k}=1, \quad 1 \leq k \leq N \\
0<\sum_{i=1}^{c} u_{i k}<N, \quad 1 \leq i \leq c \\
\left\|x_{k}-v_{i}\right\|^{2}=\sum_{j=1}^{n} \frac{\left(x_{k j}-v_{i j}\right)^{2}}{\sigma_{j}^{2}}
\end{gathered}
$$

In equation (5), $\sigma_{j}$ represents the standard deviation of the $j$-th input dimension of the input patterns, and the weighted euclidean distance provides reasonable distance information that is not significantly affected by the data size distribution. An input vector set $X=\left\{x_{1}, x_{2}, \ldots \ldots, x_{N}\right\}, x_{k} \in R^{n}, 1 \leq k \leq N$ consisting of $\mathrm{N}$ patterns in $\mathrm{n}$ dimensional Euclidean space, $V=\left\{v_{1}, v_{2}, \ldots ., v_{N}\right\}, v_{i} \in R^{n}$, cluster center, and degree of belonging to $1 \leq s \leq c$, are represented by $U=\left\{u_{i k}\right\}$, expressed by membership matrix. $u_{i k}$ and $v_{i}$ are calculated using equations (6) to (7).

$$
\begin{aligned}
& u_{i k}=\frac{1}{\sum_{i=1}^{c}\left(\frac{\left\|x_{k}-v_{i}\right\|}{\left\|x_{k}-v_{j}\right\|}\right)^{\frac{2}{m-1}}}, 1 \leq k \leq N, 1 \leq s \leq c \\
& u_{i k}=\frac{\sum_{k=1}^{N} u_{i k}^{m} x_{k}}{\sum_{k=1}^{N} u_{i k}^{m}}, 1 \leq i \leq c
\end{aligned}
$$

The fuzzy coefficient " $\mathrm{m}$ " is a very important factor that determines the type of membership function of each cluster, and generally uses 2 . If this value is less than 2 the 
overlapping area between each cluster area is reduced, and the area near 1 and 0 is increased, and as a result, the area showing the characteristic of the crisp set increases. Also, when the value is larger than 2, a fuzzy set having a sharp center point of the cluster is generated, and the difference in belonging value to each other cluster is decreased. The conclusion of the FCM-based polynomial neural network will form the rule after "then" in equation (1), which is considered to be a local regression model expressed as a polynomial function of each local domain.

The polynomial function is activated by the active value of the conditional part, and operates as a local regression model of each fuzzy rule. The reasoning part of the FCM based polynomial neural network is expressed as a fuzzy space division of conditional part, and as a local session model expressing the local area as a polynomial of the conclusion part. In the reasoning part, the final output of the network is obtained by fuzzy reasoning. This sequence is the same as the fuzzy inference process, and has the same shape as the fuzzy neural network. In conclusion, in the structure of the proposed FCMbased polynomial neural network, the final output of $\mathrm{j}(\mathrm{j}=1, \ldots$,$) -th output is expressed as$ equation (8) by fuzzy reasoning.

$$
y_{j}=g_{j}(x)=\sum_{i=1}^{c} \frac{u_{i} f_{j i}(x)}{\sum_{k=1}^{c} u_{k}}=\sum_{i=1}^{c} u_{i} f_{j i}(x)
$$

\subsection{Optimal Control Scheme in Microgrid System}

The proposed prediction model is designed to provide the efficiency as well as the cost reduction in energy use by supporting the operation of distributed power facilities. As a microgrid element technology, the power load prediction and wind power generation prediction process are planned to start at 0:00 every day (1 day and 24 hour plan). Also the charging and discharging process of energy storage device is planned to coordinate at 0:00 every day, with the power load and generation prediction process. The target devices for active devices consist of four types, such as load, solar, wind, and energy storage devices. The load controlled active devices is to control the load usage according to the schedule, the renewable energy generation amount, and the charging state of the energy storage device. Photovoltaic controlled active devices with photovoltaic inverter and interface is used to collect power generation of solar power and to cope with the crisis due to various alarms. Wind power controlled active devices with the wind power inverter and interface is used to perform the functions due to the wind power collection and various alarms.

Active energy storage devices perform the charge/discharge power control functions at intervals of 15 minutes according to the schedule by using the renewable energy generation amount and the load usage of microgrid system. The hardware configuration of active device consists of a CPU board, an I/O board, and a power board. The proposed microgrid operating system in this study is implemented with the following seven operating screens; the comprehensive real-time status screen for displaying the power supply and micro grid operating mode of the micro grid system as a whole, the system monitoring screen, the screen for monitoring the micro grid operation status, the screen for monitoring the real time development status of distributed power, the battery status display screen for displaying charging and discharging state, and a peak load screen for monitoring normal status.

Figure 2 shows the hardware configuration of the microgrid operating system. In the operation of the load pattern function, one of the average value (weekday) of one day, one week ago, one week, and the average value of one week (holiday) is selected, and the corresponding load usage is displayed. Real-time history Demand management status function, daily demand reduction and emergency reduction status are displayed in real time. A manually set energy storage plan means that the charge and discharge plan generated from the optimized package can be changed manually if the operator needs to 
change it to suit the environment.

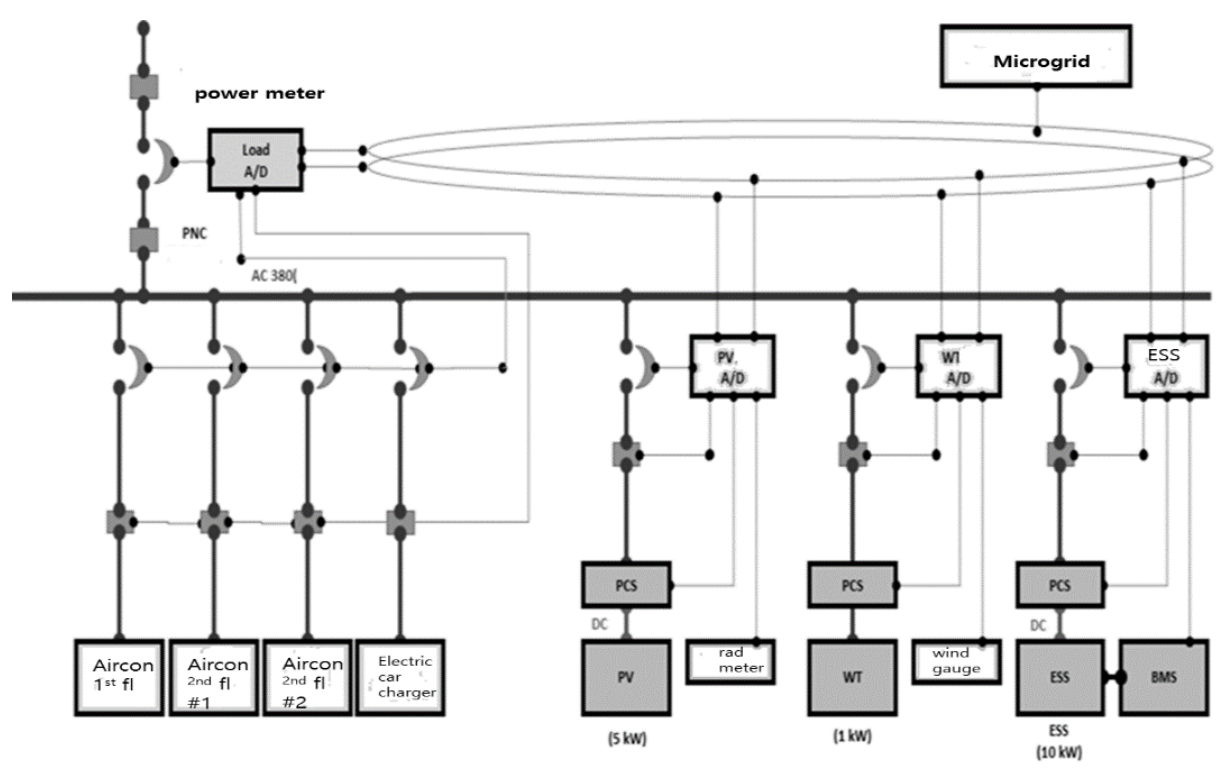

Figure 2. Hardware Configuration of Microgrid Operating System

\section{Performance Evaluation}

\subsection{Prediction Model and Simulation Data}

We designed the prediction model by applying the algorithm of polynomial neural network based on FCM. The execution interval is the periodical time according to a certain interval for prediction. The input and output of the prediction model define the types of input and output factor and the data processing method.

- Execution Time Interval: Once per day (October 10, 2015)

- Results: Predicted Values every 15 minutes from 0:00 am to 23:45 pm

The 3-hour interval data acquired from the Korea Meteorological Agency are processed at every15-minute interval using various data such as precipitation probability, precipitation type, precipitation, humidity, weather condition, 3-hour temperature, minimum temperature, daily maximum temperature, wind speed. These values are used as the input in the predictive model. In addition, 96 data sets were generated every 15 minutes through the solar radiation sensor and 96 wind speed data were generated every 15 minutes through the wind speed sensor. Also 96 power load data were generated per day and these values are used as output in the predictive model.

Table 1. Open API Data Provided by the Korea Meteorological Administration (every 15 minutes)

\begin{tabular}{|c|c|c|c|c|}
\hline Item & $3: 00$ & $3: 15$ & $3: 30$ & Explanation \\
\hline $\begin{array}{c}\text { Probability of } \\
\text { Precipitation }\end{array}$ & $30 \%$ & $31.25 \%$ & $33.75 \%$ & $(45 \%-30 \%) / 12+15$ minutes ago value \\
\hline $\begin{array}{c}\text { Precipitation } \\
\text { Type }\end{array}$ & 1 & 1 & 1 & $\begin{array}{c}\text { The same value as the value provided } \\
\text { by the Meteorological Agency }\end{array}$ \\
\hline $\begin{array}{c}\text { 6 hour } \\
\text { Precipitation }\end{array}$ & $1.8 \mathrm{~mm}$ & $1.8 \mathrm{~mm}$ & $1.8 \mathrm{~mm}$ & $\begin{array}{c}\text { The same value as the value provided } \\
\text { by the Meteorological Agency }\end{array}$ \\
\hline
\end{tabular}




\begin{tabular}{|c|c|c|c|c|}
\hline Humidity & $73^{\circ} \mathrm{C}$ & $72.75^{\circ} \mathrm{C}$ & $72.5^{\circ} \mathrm{C}$ & $(70 \%-73 \%) / 12+15$ minutes ago value \\
\hline $\begin{array}{c}\text { 6 hours fresh } \\
\text { Snow Cover }\end{array}$ & $0 \mathrm{~cm}$ & $0 \mathrm{~cm}$ & $0 \mathrm{~cm}$ & $\begin{array}{c}\text { The same value as the value provided } \\
\text { by the Meteorological Agency }\end{array}$ \\
\hline $\begin{array}{c}\text { Weather } \\
\text { Condition }\end{array}$ & 3 & 3 & 3 & $\begin{array}{c}\text { The same value as the value provided } \\
\text { by the Meteorological Agency }\end{array}$ \\
\hline $\begin{array}{c}3 \text { hour } \\
\text { Temperature }\end{array}$ & $10^{\circ} \mathrm{C}$ & $10.75^{\circ} \mathrm{C}$ & $11.5^{\circ} \mathrm{C}$ & $(19 \%-10 \%) / 12+15$ minutes ago value \\
\hline $\begin{array}{c}\text { Daily } \\
\text { Minimum } \\
\text { Temperature }\end{array}$ & $10^{\circ} \mathrm{C}$ & $10^{\circ} \mathrm{C}$ & $10^{\circ} \mathrm{C}$ & $\begin{array}{c}\text { The same value as the value provided } \\
\text { by the Meteorological Agency }\end{array}$ \\
\hline $\begin{array}{c}\text { Day Maximum } \\
\text { Temperature }\end{array}$ & $25^{\circ} \mathrm{C}$ & $25^{\circ} \mathrm{C}$ & $25^{\circ} \mathrm{C}$ & $\begin{array}{c}\text { The same value as the value provided } \\
\text { by the Meteorological Agency }\end{array}$ \\
\hline $\begin{array}{c}\text { Wind Speed } \\
\text { (East-West } \\
\text { Component) }\end{array}$ & $3.4 \mathrm{~m} / \mathrm{s}$ & $3.4 \mathrm{~m} / \mathrm{s}$ & $3.4 \mathrm{~m} / \mathrm{s}$ & $\begin{array}{c}\text { The same value as the value provided } \\
\text { by the Meteorological Agency }\end{array}$ \\
\hline $\begin{array}{c}\text { Wind Speed } \\
\text { North-South } \\
\text { Component) }\end{array}$ & $1.6 \mathrm{~m} / \mathrm{s}$ & $1.6 \mathrm{~m} / \mathrm{s}$ & $1.6 \mathrm{~m} / \mathrm{s}$ & $\begin{array}{c}\text { The same value as the value provided } \\
\text { by the Meteorological Agency }\end{array}$ \\
\hline Wind Direction & $\mathrm{N}-\mathrm{NE}$ & $\mathrm{N}-\mathrm{NE}$ & $\mathrm{N}-\mathrm{NE}$ & $\begin{array}{c}\text { The same value as the value provided } \\
\text { by the Meteorological Agency }\end{array}$ \\
\hline $\begin{array}{c}\text { Wind Speed } \\
\text { Wome value provided }\end{array}$ \\
\hline
\end{tabular}

\subsection{Experimental Results and Performance Analysis}

Sequentially changing values (temperature, humidity, precipitation probability, etc.,) among the Meteorological Agency data are converted into data of 15 minutes interval so as to have a linear change value, and while irregularly changing values such as wind speed are changed according to the flow of time are generated with 15-minute intervals as they are. Figure 4 shows the results of solar radiation prediction performance, and Figure 5 shows the results of power load prediction performance. From these results, we can see that the solar radiance prediction value and the load prediction value are very close to the measured values within 5\%, although there is a slight difference by day. In order to reduce the deviation due to the difference between some previous predicted values and the actual values, we use a modified algorithm with new predicted values. We used the data from Korea Meteorological Administration to process the data as needed for this simulation.

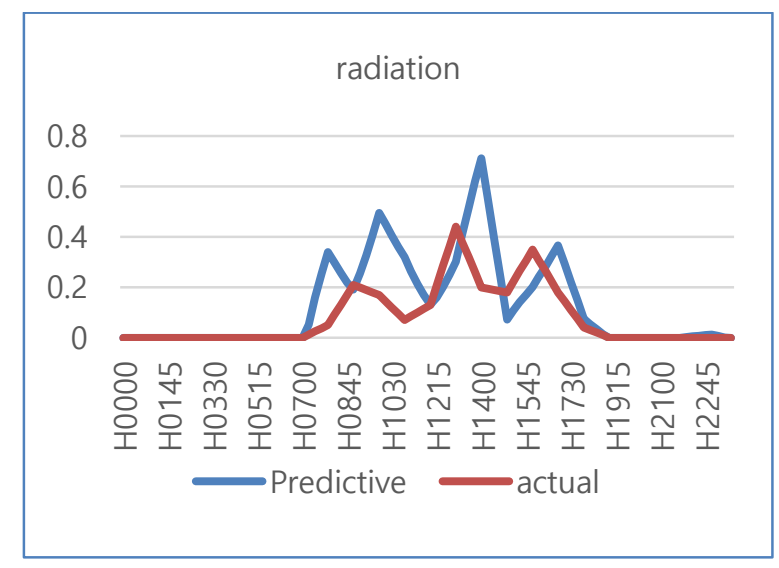

Figure 4. The Predicted Value of Solar Radiation (November 12, 2015) 


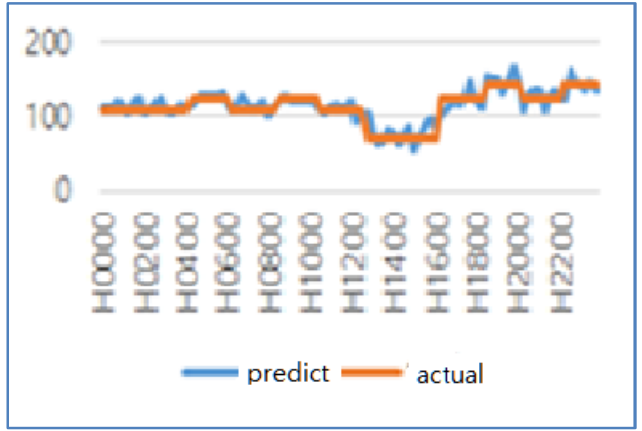

(November 11, 2015)

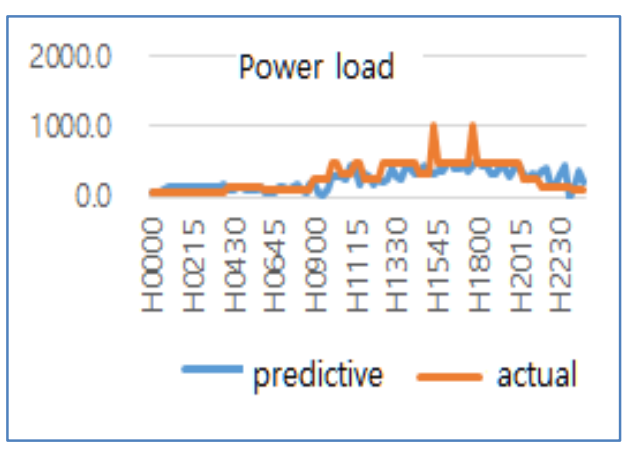

(November 12, 2015)

Figure 5. Power Load Prediction Performance Results

The function of the microgrid charge and discharge plan is based on several factors such as the generated power difference (load power - generated power), the economic power charge, the discharge plan setup, the load power consumption for 48 hours, the distributed power generation amount, and the charge rate of the energy storage device. The charging and discharging process was designed based on both the current state of the energy storage device and the plan (load, solar, wind) from the demand estimation.

The charging rate of energy storage device is in the range of $15 \% \sim 80 \%$, and the charge and discharge plan was made by considering some factors such as application of manual setting, the prevention of the peak of KEPCO, and the electric power charge information of KEPCO. The results of the charge and discharge experiment are shown in Figure 6 and Figure 7, respectively. The experiment was divided into the following two cases; the case of normal condition (solar power generation, normal operation of wind power generation facility) and the case of abnormal condition (solar power generation facility failure). Even when the new/reconditioning facility happens to fail during the operation, the charge and discharge planning can be working normally using the manual setting function. From this result, it can be seen that the discharge is started when the lead is larger than the sum of the wind power and the sunlight, and charging starts again when the solar power returns to normal condition and the load is reduced.

In addition, when the battery charge state is $20 \%$ or less and the load is increased again, the control of the KEPCO system starts and the normal charge and discharge can be performed. In the case of performing the plan correction function, the periodic execution starts at 0:00 every day and generates a plan for 48 hours in a 15-minute cycle. The correction function performs real-time correction every 15 minutes.

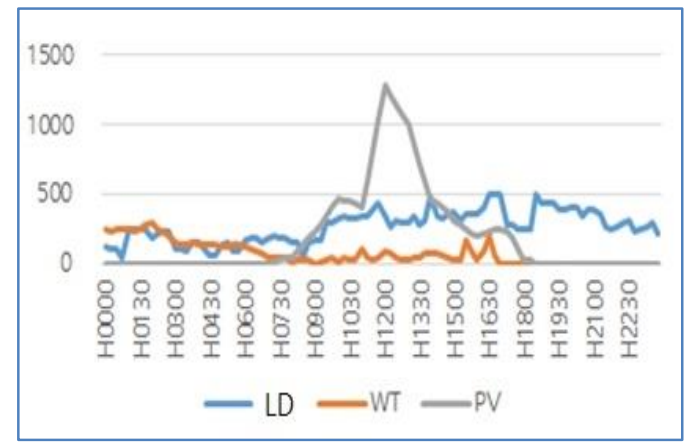

Load, Wind Power, Solar Power Generation Plan

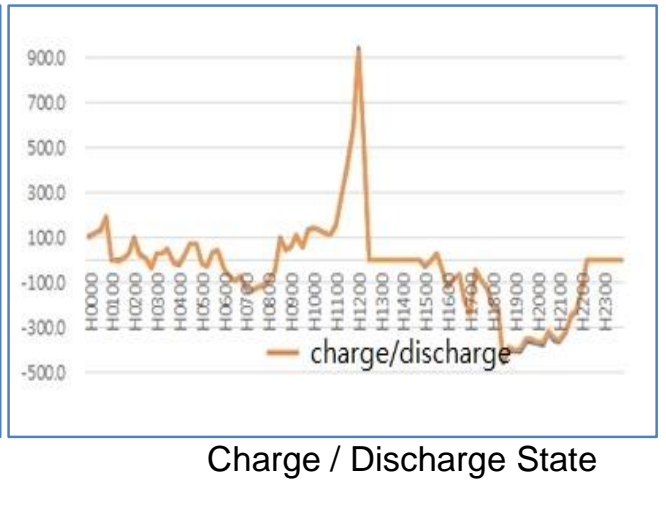

Figure 6. Charge/Discharge Plan in Normal Stage (November 10, 2015) 


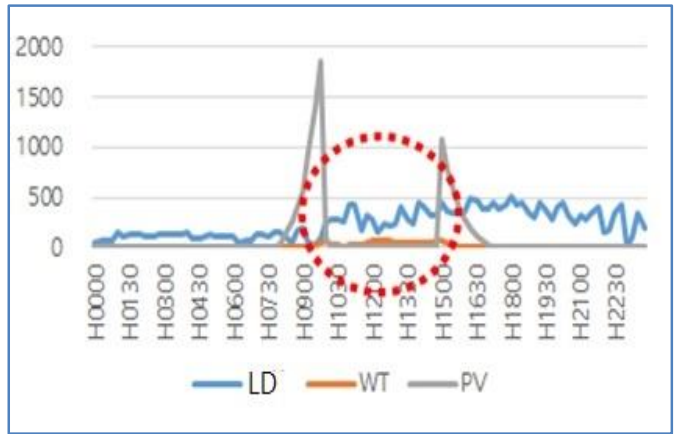

Load, Wind Power, Solar Power Generation Plan

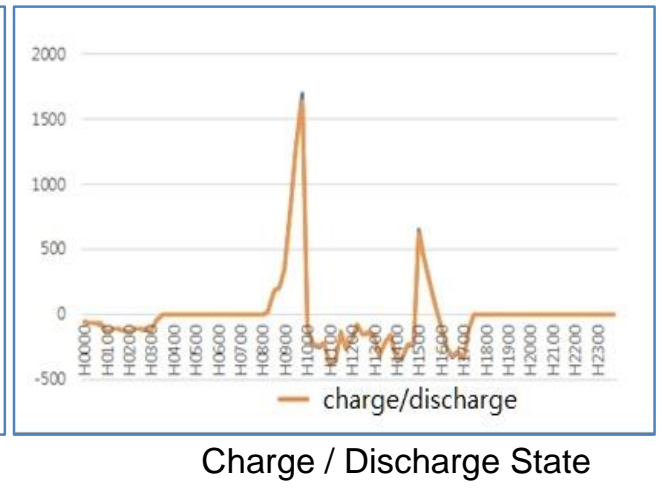

Figure 7. Charge/Discharge Plan in Abnormal Stage (November 12, 2015)

\section{Conclusion and Future Works}

This paper deals with an optimal control technique of distributed power with a predictive model, which includes the microgrid based load prediction, the distributed power generation prediction, and the charge/discharge planning for energy storage devices. In this paper, we propose an optimal control scheme to control and operate distributed power efficiently using active devices based on microgrid technology. The proposed system is designed to operate under optimal conditions by integrating operation plan and to control the efficient management of distributed power facilities in microgrid. This system also provides efficiency of energy use by supporting both the distributed power operation and the prediction of power demand in microgrid associated with renewable energy storage devices.

In addition, various experiments on charge and discharge performance were performed according to power plan with load and power generation amount. From the analysis of the results, we confirmed that it has good performance. Furthermore, even if the power facility works is in abnormal state, it is confirmed that the charge and discharge plan can be operated normally by using the manual setting function. The results of this study show that it is possible to maximize the efficiency by making use of active devices for load management, by establishing a power reduction plan and by participating in demand response market. The outcomes of this research are expected to be further improved and contributed to the improvement of competitiveness in IT and new \& renewable energy convergence using microgrid based active devices.

\section{Acknowledgments}

This paper is a revised and expanded version of a paper entitled "Distributed Power Management Scheme Using Micro-grid Technology and Predictive Models" presented at ICGHIT (International Conference on Green and Human Information Technology) 2017, Hangzhou, China.

\section{References}

[1] Q. Zhu, "Research on Development Strategies od Distributed Generation Based on Microgrid Technology", International Journal of Grid Distribution Computing, vol. 8, no. 3, (2015), pp. 179-188.

[2] 2014 New Renewable Energy White Paper, "Trends in Renewable Energy Monthly Technology (Renewable Energy)", (2014), pp. 259-262, 295-299, 326-327.

[3] Microgrid Market and Technology Trend, Korea Electric Industry Cooperative Association, Electric Information, vol. 481, (2015).

[4] J.-S. Lee, "Development of Active Device and Operating System for Distributed Power Supply", Final Report, PNC Corporation, (2015).

[5] S.-M. Kim, "Application and Operation of Micro Grid Technology", Journal of the Electric World / Monthly Magazine, (2014), pp. 38-42. 
[6] Korea Energy Corporation, "Major Policy Directions for Energy New Industry and Energy Storage Devices", (2016).

[7] J.-G. Chang and M.-S. Kang, "Distributed Power Operating System Using Microgrid Technology and Active Devices", Proceedings of Conference on Medical Electronics Convergence, (2018); Gumi, South Korea.

[8] E.-S. Kim, "Microgrid Technology Planning Special Feature (Instrument Technology)", Smart Distribution Center, Korea Electro Technology Research Institute, (2015), pp. 103-105.

[9] Korea Power Exchange, "Policy Study for the Activation of Distributed Group Energy Supply", (2014), pp. $1-18$

[10] K-BIZ Korea Electric Industrial Cooperative Association, "Electric Information", Special Issue Microgrid Market and Technology Trend, vol. 481, (2015), pp. 20-29.

[11] J.-S. Lee, "Development of Active Device and Operating System for Distributed Power Supply", Final Report, P \& C Co., Ltd., (2015).

[12] KEPCO Distribution Planning Department, "Distributed Power Distribution System Linkage Technology Guide Line”, (2015).

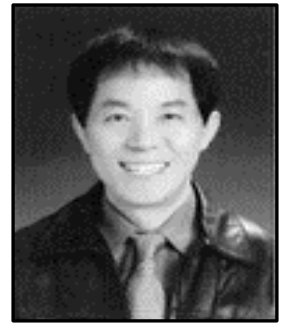

Jin-Gyu Chang, received his B.S. in Electronic Engineering from Chung-Ang University, Seoul, Korea in 1987. And he received M.E. degree in Electronic Engineering, GangneungWonju National University, Gangneung, Korea in 2017. He joined Samsung in 1987 and spent 25 years in various businesses such as organizational culture, education, production, manufacturing, purchasing, development, product planning, quality control, and strategic business. While developing the memory module product, he won 2 Jang Young-sil Award in 2005 and 2009. From 2013 to 2017, he has been providing business support services at GangneungWonju University. His interests include power demand management using smart grid, micro-junction mechanical reliability, package and PCB design, renewable energy.

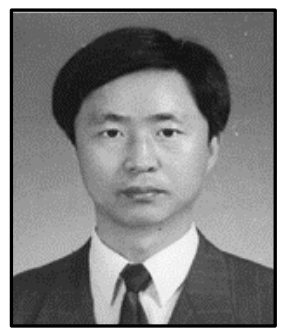

Moonsik Kang, is Professor of department of Electronic Engineering at College of Engineering, GangneungWonju National University (GWNU), South Korea. He received his B.S. and M.E. degrees in Electronic Engineering from Yonsei University, South Korea, in 1985 and 1988, respectively and his Ph.D. in Electronic Engineering from the same University in 1993. He was a post doctorate research associate at department of Electrical and Electronic Engineering, University of Pennsylvania, PA, USA. Also he worked as a research associate at department of Electronic and Computer Engineering, Illinois Institute of Technology, IL, USA. In addition, he had worked as a Researcher with Samsung Electronics, South Korea. He also served or currently serving as a reviewer and Technical Program Committee for many important Journals, Conferences, Symposiums, Workshop in computer networking area. His research interests include wired/wireless communication protocols, convergence technology for next generation networks, QoS traffic control techniques, and mobile multimedia traffic modeling and applications. 